\title{
A Different Take on Humanities
}

\author{
Włodzimierz Bolecki
}


Włodzimierz Bolecki

\section{A Different Take on Humanities}

DOI: 10.18318/td.2015.en.1.4

$\mathbf{M}$ ore and more often a "crisis of humanities" becomes the main theme of various books and articles. It has not entered public debate yet, but it is increasingly difficult to ignore the subject. However, one could say that questions about humanities are as old as its history. One could also state, with a degree of legitimacy, that the "crisis" is a fundamental subject of the tradition of modernism, understood as the 2oth-century reflection on contemporary culture. But even that broad context, explored with the help of an increasing number of concepts and models, fails to explain the intensity of today's attempts at describing problems haunting the humanities. Most importantly - it does so in the context of changes connected to a search of new formulas for higher education and research institutions. Without a doubt there are many reasons for that situation, and it is impossible to reduce them to a single cause. One should also remember, however, that the diagnoses are influenced by different contexts, in which they were formulated (social, political, civilizational, historical ones etc.).

However, one could safely say that several reemerging issues connect all those statements about humanities (I am not including their close relationship with social sciences here). I will list them randomly: the first issue is
Włodzimierz Bolecki

- professor at IBL

PAN. Specialises in the theory and the history of the literature of the 2oth/21st c. His recent publications include: Inna krytyka (2006; K. Wyka Prize); „Inny Świat” Gustawa Herlinga-Grudzińskiego (1994; 2007); Ptasznik z Wilna. O Józefie Mackiewiczu (1991; 2007, 2014, "Kultura" Prize); Modalności modernizmu (2013; nominated for the Jan Długosz Prize). Author of many editions of critical studies about inter alia W. Berent,

S. I. Witkiewicz,

A. Wat, B. Schulz,

W. Gombrowicz,

G. Herling-Grudziński. Contact: www. bolecki.eu 
concerned with a question about the specificity of the humanities, about the markers of their separateness from the so-called experimental sciences; the second one is concerned with their social justification and its place within scientific research; the third one - with their position within today's higher education structure; fourth - with their "crisis" (whatever that means); fifth with problems of their particular domains, and ways in which those domains are practiced; sixth - with a general perception of their depreciation; seventh - with their insufficient funding; eighth - never mind, let us stick with seven.

A common characteristic of all of the above listed issues is the asymmetry between the general character of the theses (spanning the entirety of humanities) and a usually modest representation of humanistic disciplines seen in those discourses. A description of the "importance" of the humanities is most often concerned with philosophy, cultural studies and philology (particularly, literary studies) - disciplines with a unique tradition of, and a potential for interpretative and theoretical reflection, and especially with theoretical-epistemological and methodological ones, notional rather than empirical.

What strikes one the most, however, is the uniquely monolithic image of the "external enemy" - all of those who, without understanding and needing humanities, have come together and agreed to work towards its demise. The list of "enemies" seems repetitive as well: commercialization and infantilization of contemporary culture, poor education, non-humanities sciences attempting to take the "spot" of the humanities, merciless fight of other (nonhumanities) departments for the biggest slice of the university's cake (sacrificing budgets of different humanistic disciplines), for the assigned hours, for the faculty, office space, etc.

The identification of obstacles and dangers faced by the humanities is always formulated in a language directed to "one's fellow people" is symptomatic. It is almost exclusively an internal discourse, often within one discipline, or several closely connected ones at best. But what is the benefit of discussing them among ourselves, if the dangers are external? What is supposed to be the practical outcome of such "humanistic autism"?

Contemporary humanities are proud of their categories, with which they describe the world: "dialogue" (and its "philosophy"), "difference" (and "diversity"), the "Other" (and "alien") - to name just a few. Within the range of individual discourses, within different areas of the social world and cultural phenomena, these categories (and interpretative languages founded on their basis) seem razor-sharp and stunning like a thunderbolt. However, when the question is concerned with presenting the specificity of the humanities in the public debate, its civilizational indispensability, and its relationship 
with other areas of sciences - the razor blade turns into a baseball bat, and thunderbolts into cheap fireworks. When reading letters and proclamations, protests and manifestos "in defense of the humanities", I always have the sensation of a 'sudden wake-up call' syndrome: "I jump to my feet suddenly, but I don't know where I am. I want to rush somewhere, maybe to the train station, maybe to work, I mistake my left hand for the right hand, my pants for my sweater, «what's that person in the mirror doing in my house?», etc.". Several decades of polishing those subtle notions, and a complete inability to communicate with "alien" and "other" disciplines, or to explain its own "otherness", as a result. Am I exaggerating? Of course I am, but it is difficult to negate the fact that the result of the jeremiads of humanists on the cult of experience, comparisons, bibliometric factors, indexes and calculations, applicability, innovation, pragmatic approach and commercialization in contemporary sciences resulted in... further alienation. Thus the particular disciplines of science, which should be connected by the concept of u n ivers it a s - a community of all sciences - seem to be dialects of different tribes, which do not know how to communicate because they did not discover that a translator is missing.

Contrary to appearances, these forces are not equal, and both sides are not on leveled positions. The "hard sciences" do not need to justify their existence (and their ever-increasing funding), and they do not need a translator. The humanities, on the other hand, constantly try to prove - with pavonine pride, although most often without results - that it can also boast the status of a science, only a "soft" one, impossible to be compared with anything else, but most importantly (and ex definitione) - better, because reflexive and valuegenerating, disinterested because impossible to be reduced to some narrow, objective-driven tasks of other particular disciplines. In the eyes of "hard" sciences, such explanations do not make the situation of the humanities any better. According to "hard" sciences, a science should be concerned with what is concrete and not undetermined, with what is empirical (verifiable), and not "because-I-said-so". A science should be interested in what is inter-subjective and not solipsistic, with what can be compared. If something cannot be compared with anything else, it might potentially be art - but it is not a science.

In an excellent essay entitled Humanities: an Unfinished Project by Michał Paweł Markowski, which can be found in this very issue of Teksty) Drugie (Second Texts), the author states (following Marta Nussbaum) that "the humanities reveal to us the relativity of what we do with the world [...] Because of that, it could take the spot of a primary science, since its subject is not that or the other, that object or the next one (literature of romanticism, cubism in painting, or an adjunct), but a human existence in its different, more or less institutionalized manifestations". That thesis must be close to every humanist's 
heart, however it is a concept which could serve as a foundation for a separate college or a department, and not an entire system of contemporary science, or higher education. Contrary to another thesis, also authored by Nussbaum, from that same excellent work: "the humanities are merely a certain critical disposition [...], since it introduces well-established lexicons used by particular disciplines into a state of crisis (or potential change), or plants doubt in the purity of every lexicon, designed to uphold the separateness of particular disciplines. Therefore the humanities is not a collective name for those various disciplines (literary studies, philosophy, art history, etc.), but an academic framework, within which those separate areas of research exist" - I believe that without negating the validity of this concept, one could act entirely in reverse.

Without questioning the subtlety of "internal" calibrations within the humanities and their disciplines (and the absolute necessity for those calibrations to last), I would like to stress only one issue - a rather obvious question of the ontological, cognitive and functional difference between the humanities and other branches of science.

Primarily, it is composed of the following assumptions: (1) the humanities, let us assume, focus on the products of human culture (works of art, actions, social phenomena, ideas, values), while non-humanities sciences focus on what is external to a man (nature, matter, etc.); (2) the humanities are, to a great extent, dependent on languages and national cultures, while for non-humanistic sciences language and culture are entirely irrelevant (language, today it is English, is a cognitively irrelevant platform of communication). Neutrinos, proteins, acids, black holes and white nights remain indifferent towards the language in which they are being described; ergo: (3) the humanities perpetually require translations into other systems of cultural meanings, while for non-humanistic sciences translation is unnecessary; (4) humanists can conduct their research together but a basis for the presentation of the results is individual expression (an article, or a book), while nonhumanistic sciences are characterized by team work, and there are instances of numerous authors assigned to a single article; (5) in the humanities, the process of writing constitutes a foundation of research and cognitive processes, and is individualized, while in non-humanities writing of an article is detached from research, and takes place after its completion. For the humanities, expression is a crucial element of content, while in other sciences it does not exist as a research question - it might occur only as a question of grammatically correct form of expression in English (or congress) language; (6) for the humanities, the history of a given discipline is not only an integral element of all its subjects and means of its research, but also - as his to ricity - it is a fundamental problem of the entire field. Whereas in the non-humanities, 
the history of a discipline has no necessary connection with present research, and rarely becomes an object of research interest. What is more: (7) publishing in the humanities (periodicals, publishing houses) is polycentric (multitude and diversity), and quality of a publication is most often not connected to the outlet, while in other sciences, publications are monocentric, which means that the outlet (a particular periodical) is a universally accepted marker of the high quality of a publication. In the humanities, a published book (monograph) is considered a measure of achievement, while in nonhumanities an article plays that same role. The humanities hold the collecting of articles written over many years into a single book (finis coronat opus) as its standard, while in the non-humanities the publishing of the same article once again is unacceptable. (8) In the humanities novelty can mean a return to works of the past, and their reinterpretation (or even simply their recollection), however there is no need to go back to the past in non-humanities, since discoveries are ruled by the principle of "first come, first served". That is enough.

The point is that these differences are as much obvious as they are banal, and have been formulated at different times, and in different circumstances. OK, well, - somebody might ask - but what is the practical conclusion coming from such a division? As far as the issues associated with the peculiar nature of the humanities and their particular disciplines, this division has marginal importance. However, this division might be a strong argument, particularly for comparisons with "hard" sciences, and particularly for the thesis about the (non) sense of financing humanities and social studies (together with the practical results of those theses) that are currently debated.

The thesis about man-created works (ontologically different than the "works" of nature), and the linguistic entanglement of the humanities, turns them into a "hard" foundation for describing their autonomy. These are not "imagination", “sensibility", “disinterestedness", "poeticism", "talent”, "ideas", "inexpressibility", "historicity", "duty", "thinking", "critical disposition", (and sometimes non-critical...) and other similar, but always justified, descriptions, but rather the ontological, cognitive and methodological differences firmly anchored in the linguistic nature of the entire field of disciplines, which creates a limes between the humanities (and social studies), and the nonhumanities. This polar division fits popular practices in both fields of science, but the problem lies in the fact that it is not obvious. Are we not dealing with works of man in the, so-called, "hard sciences" (for example, in biology, chemistry, mechanics)? Are chemical compounds, materials, machines, etc. not man-made, just like a poem or a painting? Such confusion, however, turns out to be helpful. Wherever man-made objects come into the picture, the humanities and experimental sciences are "hard" all the same, since they ask about 
the same thing: how are the creations of man's cognitive activity made, and what are their social functions?

Internal differences (huge ones) between particular disciplines within the range of each of those fields are secondary in respect of that primary division. If we were to agree with such a polar division between "hard" and "soft" (here: hardened) disciplines of science, and simultaneously with their "identicality" in respect of examining human creations, the next step - to finish this introduction - would be to pose two theses.

The first one: for more than a century the humanities were not able to firmly establish its discoveries concerning the system, functions and meanings of language in all spheres of human activity in the broad social consciousness (in this case: in the consciousness of "hard" scientists). The "linguistic turn" became an irrelevant and meaningless label for the fads in the humanities, just like all the other ones. As a result, today, while every schoolchild knows what does the discovery of proteins, chromosomes, genes, atoms, elemental particles, DNA, etc. mean for science, the common knowledge about language and the discoveries of linguistics (from distinctive features and phonemes, through semantics and syntax, to questions of ethnolinguistics, cognitive science and neurolinguistics, or even more importantly the cultural, mental, linguistic and communicative determinants of semantics) is reduced to a statement that ... well, "people talk", somehow. When, for example, chemistry, biology, physics, mathematics, etc. were establishing their image as the most important branches of cognitive search for man, and necessary for the civilizational progress, humanists (maybe with an exception for historians) kept affirming the image of their disciplines as spaces for activities, which are civilizationally irrelevant, unproductive and de facto obsolete. For that, all humanists should wear sackcloth and ashes, and flog themselves until their circulation (of thoughts) gets better. The decision of many years ago, made by the Polish government, to dedicate funds from the European Union (the so-called structural funds) solely towards Info-Bio-Tech disciplines was an effect of that honestly earned, permanent depreciation of humanities, and simultaneous nursing of barren jeremiads ("they took it away, kind sir, they cut our funding, took our post-doctoral degree"), as well as of self-satisfaction and "autism of argumentation", or "autism of presence" in matters crucial for the very foundations of the existence of the humanities and social sciences in Poland. As a result of this (accompanied by a complete silence of the scientific community and all of its representative bodies), not a single dime from over four billion zlotys received for scientific research from Brussels (for all sciences), have been spent on humanities and social sciences (as well as on mathematics and theoretical physics). Within a year, or two, new decisions will be made, regarding another tranche of structural funds. 
And now for the second thesis: the humanities, in order to be revitalized (in every sense of the word) and to redefine their position, need a renewed model (if it ever had any to begin with) of research - not only an interdisciplinary model, but also an inter-domain one'.

"The horn, $[. .$.$] bore the music into the forest and an echo repeated it".$

Translation:Jan Pytalski

1 I write about that model with Przemysław Urbańczyk in a separate article that is being prepared for publication. 